the right of the American constituents to exercise their inalienable rights, but also conducted a veiled attack on the rights of the working class in America. In this regard, it is of particular interest to analyze the topic of evolution of suppression mechanisms, being developed all the time in the west, relying on the discipline of political analysis and forecasting to estimate the possible outcome of the Donald Trump's legacy in the historical context of the larger set of events.

Keywords: politics, power, social engineering, political analysis and forecast, United States

ШАЛЫГИНА Наталья Валентиновна - кандидат исторических наук, старший научный сотрудник Института этнологии и антропологии им. Н.Н. Миклухо-Маклая РАН (119334, Россия, г. Москва, Ленинский пр-кт, 32A; etgender@mail.ru)

ПОЛОЖЕНЦЕВА Ирина Вениаминовна - кандидат экономических наук, доцент кафедры педагогики и психологии профессионального образования Института социально-гуманитарных технологий Московского государственного университета технологий и управления им. К.Г. Разумовского (Первый казачий университет) (109004, Россия, г. Москва, ул. Земляной Вал, 73; vipperh@yandex.ru)

\title{
ИНТЕГРАЦИОННЫЙ ПОТЕНЦИАЛ УКРАИНЦЕВ В США (ПОСТСОВЕТСКИЙ ПЕРИОД)
}

\begin{abstract}
Аннотация. В статье рассматриваются особенности двух последних иммиграционных волн граждан Украины в США, начавшихся после распада Советского Союза в 1991 г. (четвертая волна) и событий на Майдане в 2014 г. (пятая волна). Основная масса украинских эмигрантов постсоветского периода, выстраивая свою стратегию переселения в США, в основном опиралась на американские законы об иммиграции, которые значительно облегчали переселенцам устройство на новом месте. Однако не меньшее участие в адаптации украинцев в США принимали и украинские организации и фонды, созданные еще первыми переселенцами с Западной Украины и поддерживающие национальный язык и культуру за рубежом. Общественные организации, созданные в США за последние три десятилетия восточными украинцами, поддерживают развитие науки и образования среди представителей украинской диаспоры. Распространенное мнение, что украинцы в США широко инкорпорированы в американскую науку, образование и структуры американской власти, не подтверждаются фактами, хотя отдельные случаи успешной интеграции представителей украинской диаспоры в социально-экономическую и политическую структуру США действительно имеют место. Украинская диаспора стремится к сохранению украинского языка и украинской идентичности в США, несмотря на то что большинство постсоветских иммигрантов из Украины в подавляющем большинстве сегодня в повседневном общении используют русский язык.
\end{abstract}

Ключевые слова: украинцы, общий советский менталитет, особенности волн эмиграции украинцев, деятельность украинских организаций в принимающих странах, сохранение украинской идентичности за рубежом, профессиональная реализация представителей украинской диаспоры в США

Ч етвертая волна украинской иммиграции, начавшаяся после 26 декабря 1991 г., т.е. после официального распада Советского Союза, самими украинскими исследователями квалифицируется прежде всего как «освобождение от экономических и политических оков коммунистического правления» [Bilan 2017: 230-231]. Крах коммунизма, по мнению украинских экспертов, «создал экономический вакуум, к которому каждая из бывших советских республик была плохо подготовлена». Конкретно украинская экономика после развала СССР называется «больным человеком Европы» и «потенциально несостоятельным государством из-за геополитического положения, 
исторического бремени и допущенных ошибок в институциональном развитии и политике»1.

Совместное хозяйствование на протяжении нескольких десятков лет вкупе с единой идеологией государства не могло не сказаться на формировании общего менталитета почти трех поколений советских людей. По образному выражению одного из участников сетевой дискуссии, критически настроенного по отношению к идеологии СССР, «менталитет советского человека умирал частями, но до сих пор не исчез... и непонятно, что должно случиться, чтобы исчез последний носитель этого менталитета» ${ }^{2}$. Идеологическая составляющая феномена советского менталитета, по мнению многих российских исследователей, предопределила его устойчивость во времени и сформировала идейно-политическую, морально-психологическую и организационную ригидность, неготовность общества к переменам, что и проявилось в полной мере в перестроечные и постперестроечные годы [Баталов 1995; Иванов 2003: 45-47]. Бесспорно, этот менталитет продолжил существовать даже после развала СССР, формируя идентичность абсолютного большинства населения некогда единой страны. И украинцы, эмигрировавшие в США после 1991 г., не являлись исключением. Их переселение за океан в этот период едва ли можно назвать экономической эмиграцией в полном смысле этого слова, учитывая общую неподготовленность к самостоятельной деятельности в капиталистических условиях и полную дезориентацию в глобальных геополитических переменах, происходивших на территории бывшего СССР.

По этой причине основная масса украинских эмигрантов четвертой волны, выстраивая свою стратегию переселения в США, в основном опиралась на американские законы об иммиграции, которые значительно облегчали переселенцам устройство на новом месте. Иммиграционные законы США имеют множество нюансов, ограничений и квот, которые, с одной стороны, ограничивают иммиграционные потоки, а с другой, - наоборот, облегчают некоторым категориям населения других стран переезд в США. Одним из таких нюансов стало принятие конгрессом США так называемой поправки Лаутенберга/Спектора, которая изначально была нацелена на облегчение эмиграции из стран ЮгоВосточной Азии и немного позже - из республик бывшего Советского Союза. Поправка ежегодно продлевается, правда, с конъюнктурными ограничениями, в зависимости от геополитической ситуации в целом.

Высокий уровень иммиграционной активности украинцев в начале нулевых годов по сути отражал именно конъюнктурные изменения в международной политике, чем объясняется решение правительства США дать отдельное определение беженцам из бывшего Советского Союза и выделить для них особую квоту (14 тыс. чел.). Во многом благодаря именно этой квоте с 2001 по 2003 г. из Украины в США выехали 17595 беженцев. Однако уже к 2004 г. международная ситуация снова изменилась, и фокус иммиграционной политики США поменялся в пользу беженцев из Африки, Восточной Азии и Ближнего Востока. Число украинских беженцев в США в 2009 г. упало ниже 1000 чел., а в 2013 г. составило всего 227 чел. ${ }^{3}$ Очередная волна иммиграционной активности украинцев произошла уже после 2014 г. Число украинских беженцев в 2015 г. уве-

\footnotetext{
${ }^{1}$ Sutela P. The Underachiever: Ukraine's Economy Since 1991, Carnegie Endowment for Int'l Peace. Mar. 9, 2012. URL: https://carnegieendowment.org/2012/03/09/ underachiever-ukraineseconomy-since-1991-pub-47451; https://perma.cc/STC2-BK84

2 Коноплев А. Что такое «советский менталитет»? Доступ: https://yandex.ru/q/question/ chto_takoe_sovetskii_mentalitet_0fda3fdd/ (проверено 12.10.2021).

${ }^{3}$ U.S. Dep't of State et al., Proposed Refugee Admissions for Fiscal Year 2010, at 5 tbl. I (2010) supra note 20
} 
личилось до 1451 чел., а в 2017 г. достигло своего пика - 4264 чел., в 2019 г. - 1547 чел. Эта цифра превысила совокупное число беженцев в США из стран Ближнего Востока и Центральной Азии за 2019 г. ${ }^{1}$ Сами украинские эксперты наиболее значимой характеристикой этой пятой волны считают позиционные изменения в отношении использования так называемой беженской политики США. По свидетельству украинских экспертов, граждане Украины «дома не сталкиваются с преследованием, которое обычно ассоциируется с определением беженца», но при этом все-таки используют беженскую программу для эмиграции в США.

Украинская иммиграция в СШАактивно поддерживается целым рядом общественных организаций, фондов и т.п. Наиболее устойчивыми и разветвленными организациями являются те, которые были созданы представителями первых волн иммигрантов, - церкви и братские ассоциации. Крупнейшим и самым богатым среди братств считается Украинский народный союз, объединяющий около 85 тыс. чел. На базе этой организации издается старейший и наиболее читаемый американскими украинцами еженедельник «Свобода», а также информативный англоязычный «Украинский еженедельник». Не менее активную общественную деятельность проводит Украинский братский союз (ранее - Украинская рабочая ассоциация), издающий газету «Народная воля» и журнал «Форум». Кроме того, в США действует Ассоциация украинских католиков, насчитывающая более 19 тыс. чел. и издающая свою ежедневную газету «Америка». Долгое время самым представительным и координирующим органом всех украинских организаций США считался Комитет конгресса украинцев Америки. Однако в 1980 г. в этой организации произошел раскол, в результате которого была создана Координационная рада украинцев Америки, в полномочия которой уже не входило право представлять интересы всех украинских организаций в США.

Традиции перечисленных украинских братств, или общин, как их нередко называют между собой сами украинские иммигранты в США, корнями уходят в историю создания и функционирования общественных организаций на территории Западной Украины и отличаются четко выраженным пониманием своих целей и задач, отражающих этнические особенности самосознания галичан и буковинцев [Музыченко 1995]. Но среди украинских организаций в США немало и таких, которые создавались восточными украинцами, например, Украинская свободная академия наук, Объединенная демократическая украинская молодежь (ОДУМ) и др. Кроме того, в США функционируют многочисленные профессиональные сообщества, объединяющие украинских инженеров, врачей, профессоров, учителей, журналистов, бизнесменов. Практически в каждой общине существуют свои молодежные танцевальные ансамбли, хоры, драматические кружки, которые не только сохраняют украинскую культуру, но и позволяют ей активно развиваться в инокультурной среде.

Особое место в формировании идентичности украинских иммигрантов США принадлежит науке и образованию. Среди научных учреждений, созданных украинскими иммигрантами, наиболее известными являются Гарвардский украинский исследовательский институт, Украинская академия искусств и наук, Научное товарищество им. Т.Г. Шевченко» и др. Гарвардский украинский исследовательский институт был создан в 1973 г. Он издает «Гарвардский журнал украинских исследований», серии коллективных научных трудов, бюллетень «Перспективы современной Украины» и т.п. Еженедельно проводятся семинары по украинской тематике, а с 2001 г. - тематические встречи с иссле-

1 Ibid. 
довательскими группами, разрабатывающими актуальные проблемы в сфере политики и сохранения украинской идентичности.

Украинская академия искусств и наук была основана еще в 1950-х гг., но ее деятельность заметно активизировалась лишь в последние годы. Академия является некоммерческой организацией и представляет собой ассоциацию ученых, специализирующихся на «украинских исследованиях» в Соединенных Штатах. Официальным периодическим печатным органом Академии является журнал «Анналы Украинской академии искусств и наук в Соединенных Штатах». Академия предоставляет возможности для научных изысканий как для украинских исследователей, так и для американских украинистов. Практически все памятные даты украинской иммиграции в США и самой Украины в Академии отмечаются здесь как важные события с привлечением известных лиц и широкой публики. В 1990-х - нулевых годах в Академии актуализировались семинары по консультированию поступающих в вузы США или по оказанию помощи в поисках работы. Поэтому авторитет Академии постепенно возрастал, привлекая все больше молодежи и формируя в их сознании лояльность украинским институтам в США.

Приблизительно в том же ключе функционирует и Научное сообщество им. Шевченко. SSS - одна из старейших академических организаций украинцев США, основанная еще в 1873 г. во Львове. Ликвидированное советской властью в 1939 г. Научное сообщество $S S S$ в 1947 г. было восстановлено уже на территории США, сохранив не только принципы и идеологию своей организации, но и архивы с материалами по истории Украины (включая историю украинской диаспоры), а также специализированную библиотеку и коллекции произведений искусства, находящиеся сегодня в штаб-квартире этой организации в г. Нью-Йорке. Одной из важнейших функций $S S S$ является финансирование научных конференций, симпозиумов, стипендий, еженедельных публичных лекций по украинской тематике при тесном сотрудничестве в этом смысле с крупнейшими американскими научными институтами, занимающимися украинскими исследованиями.

Активная деятельность (особенно после 1991 г.) такого числа украинских научных учреждений в крупных городах США свидетельствует о том, что украинская иммиграция четвертой волны к началу нулевых годов уже обладала весьма внушительными инструментами воздействия на молодежь своей диаспоры, тем самым обеспечивая преемственность в сохранении украинской идентичности среди новых поколений. Созданные совместными американоукраинскими усилиями условия для максимальной поддержки адаптации украинской молодежи в США в ближайшей перспективе способны привести к еще большему осознанию ею психологических и социальных преимуществ принадлежности к своей этнической группе и осознанному сохранению украинского языка в инокультурной среде.

Фактор широкой диаспоральной поддержки украинства при одновременном участии в этом процессе официальных американских структур стал играть особенно заметную роль в судьбе именно представителей четвертой и пятой волн украинской иммиграции. Предыдущим поколениям украинцев в США пришлось столкнуться с серьезными трудностями в своем стремлении сохранить идентичность, что объясняется прежде всего их преимущественно низким социально-экономическим статусом, а также ассимиляторским характером американского образования, нацеленного на проведение политики «плавильного котла» в США.

Наплыв «перемещенных лиц» после Второй мировой войны и затем, в конце 1980-х - начале 1990-х гг, т.е. после прекращения существования СССР, изме- 
нил ситуацию. В США из Украины эмигрировали в основном хорошо образованные люди, нередко владеющие английским языком. Сочетание благоприятствующих иммиграции факторов в эти годы способствовало появлению мифа о существовании будто бы «могучей» украинской диаспоры в США, способной оказывать любую организованную помощь соотечественникам, прибывающим на новое место жительства. Но в реальности «могучая» украинская диаспора в США, несмотря на все усилия ее активистов, все же имеет как минимум два слабых места - радикальный водораздел межпоколенных ценностей и не менее радикальные различия между западным и восточным крыльями диаспоры.

По словам Игоря Винниченко, историка, этногеографа, директора общественного Института исследования диаспоры (Иллинойский университет США), «многие украинские общины за рубежом так и не могут наладить друг с другом полноценное сотрудничество... Представители четвертой волны украинцев-эмигрантов нередко идут за помощью к русским, еврейским, польским общинам, а не к украинским. Не секрет, что многие из них не владеют свободно родным языком и не особо хотят его изучать, чтобы полноценно общаться с украинской диаспорой... Стартовые условия на новой родине для них складываются не совсем благоприятно. По-видимому, в такой ситуации им не до разного рода фольклорно-этнографических или культурно-образовательных и воспитательных акций, регулярно проводимых украинскими общинами»1.

Еще одним мифом о влиятельности украинской диаспоры в США можно считать представление о том, что наиболее успешные ее члены инкорпорированы в структуры американской власти. Но, как полагает И. Винниченко, изучавший этот вопрос в 1993 г., в то время лишь несколько человек достигли относительно высокого положения на политическом олимпе в США, и они скорее представляли собой исключение, чем правило. Среди высокопоставленных американских политиков можно упомянуть первого чрезвычайного и полномочного посла США в Украине Романа Попадюка (1992-1993 гг.), дивизионного генерала армии США, советника министра обороны Мыколу Кравцива и др. Однако имена высокопоставленных американских украинцев основной массе представителей диаспоры в США неизвестны и, судя по разговорам с представителями украинской диаспоры, на их повседневную жизнь высокопоставленные политики и чиновники украинского происхождения не оказывают какого-либо заметного влияния. Приблизительно таким же образом обстоит дело и с успешными иммигрантами в американском бизнесе. Если в Канаде некоторым украинским иммигрантам удалось построить мощные финансовые империи (например, Евгений Мельник, миллиардер, владелец клуба НХЛ «Оттава Сенаторс»), то в США их экономической основой стал малый и средний бизнес в пищевой промышленности и туризме, а также церковь, кредитные союзы, банки и магазины. В крупном бизнесе себя реализовали единицы американских украинцев, но их успех получил достаточно весомый общественный резонанс и в той или иной мере повлиял (и продолжает влиять) на укрепление этнической идентичности иммигрантов в целом. Значительных успехов в США добился, например, Джон Гинянский, владелец компании Winner Group в Делавере (штат Пенсильвания), занимающейся продажей брендовых автомобилей (Ford, Volvo, Land Rover, Jaguar и Porsche), а также строительным бизнесом (Winner Construction). Еще одним известным украинским иммигрантом считается Майкл Блейзер, переехавший в США из

1 Vynnychenko I. Ukrainians of the Eastern Diaspora: An Atlas, 1993. Доступ: https://www. gettextbooks.com/isbn/9780920862902/ (accessed 12/10/2021). 
Советского Союза в 1978 г. и уже к началу 1980-х гг. ставший, по версии Forbes, одним из четырех наиболее успешных эмигрантов из Советского Союза, главой (с 1993 г.) Международной инвестиционной компании SigmaBleyzer. Престиж крупного украинского бизнеса в США работает на укрепление идентичности еще и в том смысле, что свои активы бизнесмены нередко переводят на историческую родину, т.е. на Украину. Так, к началу нулевых годов крупнейшими украинскими активами SigmaBleyzer стали телекоммуникационная компания «Воля», Севастопольский морской завод, «Полтава-кондитер», Запорожский мясокомбинат, Мелитопольский завод тракторных гидроагрегатов и разработчик информационных систем управления «Софтлайн».

Успешные украинские иммигранты в США гордятся своим происхождением больше, чем их соотечественники, живущие на родине. Последние порой воспринимают восхищение иммигрантов своей принадлежностью к украинской нации как «чудачество», как и их новые жизненные ценности и приоритеты, связанные с языком, отношением к религии и т.п.

Неравнозначность волн иммигрантов объективно создает почву для более интенсивной их ассимиляции, особенно в те периоды, когда численность прибывающих резко снижается. Одним из показателей ускоренной ассимиляции и утери идентичности чаще всего становится отказ от использования родного языка в повседневной практике. В 1980 г., например, из 730 тыс. жителей США украинского происхождения (сюда не входят около 500 тыс. наследников закарпатских русинов) только 123 тыс. назвали родным языком украинский.

Такая ситуация сложилась в силу того, что украинским эмигрантам удобнее вне работы общаться на русском, число носителей которого доминирует. Однако заслуживает уважения стремление украинцев сохранять украинскую идентичность на территории принимающей стороны - США, где в официальной сфере доминирует английский, а в домашнем общении - русский.

\section{Список литературы}

Баталов Э.Я. 1995. Советская политическая культура. - Общественные науки и современность. № 3. С. 60-70.

Иванов В.Н. 2003. Политическая социология. М.

Музыченко П. 1995. Исторические источники современного этапа развития местного самоуправления в Украине. - Юридический вестник. № 2.

Bilan Yu. 2017. Migration of the Ukrainian Population: Economic, Institutional, and Sociocultural Factors. London: Ubiquity Press. 318 p.

SHALYGINA Natalia Valentinovna, Cand. Sci. (Hist.), Senior Researcher at the Institute of Ethnology and Anthropology RAS (32a Leninsky Ave, Moscow, Russia, 119334; etgender@mail.ru)

POLOZHENTSEVA Irina Veniaminovna, Cand. Sci. (Econ.), Associate Professor of the Chair of Pedagogy and Psychology of Professional Education, Moscow State University of Technology and Management named after K.G. Razumovsky (First Cossack University) (73 Zemljanoj Val St, Moscow, Russia, 109004; vipperh@yandex.ru)

\section{INTEGRATION POTENTIAL OF UKRAINIANS IN THE USA (POST-SOVIET PERIOD)}

\footnotetext{
Abstract. The article examines the features of the last two immigration waves of Ukrainian citizens to the United States, which began after the collapse of the Soviet Union in 1991 (the $4^{\text {th }}$ wave) and the events on the Maidan in 2014 (the $5^{\text {th }}$ wave). The bulk of Ukrainian emigrants of the post-Soviet period, building their resettlement strategy in the United States, mainly
} 
relied on American immigration laws, which greatly facilitated settlers in a new place. However, Ukrainian organizations and foundations, created by the first settlers from Western Ukraine and supporting the national language and culture abroad, also took part in the adaptation of Ukrainians. Public organizations created in the United States over the past three decades by Eastern Ukrainians support the development of science and education among representatives of the Ukrainian diaspora. The widespread opinion that Ukrainians in the United States are widely incorporated into American science, education and the structure of American power is not supported by the facts, although individual cases of their successful integration do take place. The Ukrainian diaspora strives to preserve the Ukrainian language and Ukrainian identity in the United States, despite the fact that the majority of post-Soviet immigrants from Ukraine in the overwhelming majority today use Russian in everyday communication.

Keywords: Ukrainians, general Soviet mentality, peculiarities of waves of Ukrainian emigration, activities of Ukrainian organizations in host countries, preservation of Ukrainian identity abroad, professional implementation of representatives of Ukrainian diaspora in United States

САФОНОВА Наталия Вячеславовна - младший научный сотрудник Института востоковедения РАН (107031, Россия, г. Москва, ул. Рождественка, 12/1, cmp. 1, safonovanat@gmail.com)

\title{
ДИСКУССИИ О ПРОБЛЕМЕ РАДИКАЛИЗАЦИИ ИСЛАМА ВО ФРАНЦИИ НАЧАЛА ХХІ в.
}

\begin{abstract}
Аннотация. Начиная с 70-х гг. прошлого века исламские радикалы периодически организовывали нападения на мирное население Франции. Самыми массовыми по числу жертв стали теракты, совершенные в ноябре 2015 г. С тех пор дискуссии об исламистах, иммиграционной политике заполнили не только франкоязычные, но и мировые СМИ. Среди исследователей, изучающих современных мусульманских иммигрантов и феномен экстремизма, наиболее известны Ж. Кепель и О. Руа. Их полемику на тему радикализации ислама или исламизации радикализма чаще всего приводят ученые и журналисты, чтобы объяснить появление и распространение исламских экстремистских идей среди иммигрантов. В статье автор рассматривает основные дискуссии по проблеме радикализации ислама, которые ведутся с начала XXI в., и то отражение, которое они нашли в современном медийном дискурсе.
\end{abstract}

Ключевые слова: исламизм, Франция, исламский экстремизм, радикальный ислам, радикализация ислама

B о Франции проживают около 5,43 млн мусульманских мигрантов, и это число постоянно растет: каждый год ислам принимают около 3600 чел., что делает ислам второй религией после христианства. Мусульмане, проживающие на территории страны, этнически многообразны. Большинство из них представлено иммигрантами из Магриба (примерно $80 \%$ общего числа), из которых 40\% - выходцы из Алжира, почти 30\% - из Марокко, остальные - из Черной Африки [Бибикова 2015: 275]. Что касается практикующих мусульман, то их число также растет: согласно опросам, в 2006 г. на приоритет мусульманской идентификации по отношению к гражданской указали 46\%, а в 2013 г. 75\% [Жолудева 2019: 134]. Также растет число мусульман, разделяющих исламистскую радикальную идеологию, как и число людей, принимающих радикальную версию ислама.

Проблема радикализации является предметом многолетней полемики двух выдающихся исследователей современного ислама - Оливье Руа и Жиля Кепеля. О. Руа считает, что к причине появления радикалов исламизм имеет мало отношения: он разрабатывает концепцию исламизации радикализма, где 